Mal J Nutr 25(3): 435-444, 2019

\title{
Diabetes literacy and knowledge among patients with type 2 diabetes mellitus attending a primary care clinic in Seremban, Malaysia
}

\author{
Lee Ching $\mathrm{Li}^{{ }^{*}}$, Winnie Chee Siew Swee ${ }^{1}$, Kanimolli Arasu ${ }^{1}$, Kwa Siew Kim ${ }^{2}$ \& \\ Siti Zubaidah Mohd $\mathbf{A l i}^{3}$ \\ ${ }^{1}$ Nutrition and Dietetics Division, School of Health Sciences, International Medical \\ University, Kuala Lumpur, Malaysia; ${ }^{2}$ Department of Family Medicine, School of \\ Medicine, International Medical University, Kuala Lumpur, Malaysia; ${ }^{3}$ Department \\ of Non-Communicable Diseases, Family Medicine Specialist, Klinik Kesihatan \\ Seremban, Negeri Sembilan, Malaysia
}

\begin{abstract}
Introduction: Good health literacy and knowledge are associated with improved outcomes in diabetes. The purpose of this study was to determine diabetes-specific literacy and knowledge levels, and its associated socio-demographic factors, among adults with type 2 diabetes mellitus (T2DM). Methods: This cross-sectional study was conducted among 196 adults from the Indian, Chinese, and Malay ethnic groups with T2DM who attended a primary care clinic in Seremban, Malaysia. The Literacy Assessment for Diabetes and Diabetes Knowledge Test 2 were used to assess diabetes-specific literacy and knowledge, respectively. Results: The majority of participants $(75.0 \%)$ had literacy scores that corresponded to Ninth Grade Level but only $3.6 \%$ of participants had a good knowledge of diabetes. Literacy scores explained up to $19.8 \%$ of the variance in knowledge scores $(r=0.445, p<0.01)$. Indian participants had the lowest literacy and knowledge scores when compared to Chinese and Malays ( $p<0.05)$. Participants with higher education had better literacy and knowledge scores $(p<0.05)$. Educational level was more likely than ethnicity to predict both literacy and knowledge scores $(p<0.001)$, while gender and age did not significantly predict either score. The majority of participants could answer general questions about physical activity, diabetes-related complications and healthy eating. Knowledge of diabetes and its relation to specific foods and the effect of diet on glucose control were limited among the participants. Conclusion: Education and ethnicity were associated with literacy and knowledge on diabetes. There existed a deficit of diabetes-related nutrition knowledge among the participants. These findings may help healthcare providers tailor individualised patient educational interventions.
\end{abstract}

Keywords: Diabetes literacy, diabetes knowledge, type 2 diabetes

\footnotetext{
*Corresponding author: Dr. Lee Ching Li

Nutrition and Dietetics Division, School of Health Sciences, International Medical University

Jalan Jalil Perkasa 19, Bukit Jalil, 57000, Kuala Lumpur, Malaysia

Tel: +60-3-27317249; Fax: +60-3-86561018; e-mail: chingli_lee@imu.edu.my

doi: https://doi.org/10.31246/mjn-2019-0031
} 


\section{INTRODUCTION}

Malaysia has the highest prevalence of diabetes mellitus (DM) among the 13 countries in the Western-Pacific region (Whiting et al., 2011). Over a period of 10 years, the prevalence of type 2 diabetes mellitus (T2DM) among Malaysian adults increased from $11.6 \%$ to $17.5 \%$ of the population but only $<15 \%$ of these patients met their glycaemic targets of glycated haemoglobin ( $\mathrm{HbA} 1 \mathrm{c}$ ) of $<6.5 \%$ (IPH, 2015; Letchuman et al., 2010; Mafauzy et al., 2016).

Factors that contribute to poor glycaemic control in patients with diabetes include poor self-care management and medication, and a failure to adhere to dietary and lifestyle prescriptions. This behavioural inertia can be attributed to low health literacy. Health literacy is defined as the patient's capacity to obtain, understand and act upon health information (Nielsen-Bohlman, Panzer $\&$ Kindig, 2004). Health literacy affects people's ability to navigate the healthcare system, engage in self-care and chronicdisease management, and may, in turn, also affect the way knowledge about diabetes is understood and remembered for application at a later time (Powell, Hill \& Clancy, 2007; Bains \& Egede, 2011). Patients with diabetes who lack adequate health literacy and knowledge have a higher risk of poor glycaemic control and microvascular complications (Phillips, Rahman \& Mattfeldt-Beman, 2018; Saeed et al., 2018).

The current knowledge of health literacy in Malaysia may not be sufficient as previous studies were limited to the use of non-diabetes specific health literacy tools and mostly involve healthy individuals (Rajah, Hassali \& Murugiah, 2019). The purpose of this study was to address this gap and to determine diabetes-specific literacy and knowledge levels, and its associated socio- demographic factors, among adults with T2DM.

\section{MATERIALS AND METHODS}

\section{Participants}

This cross-sectional study was conducted among adult patients with a confirmed diagnosis of T2DM attending a government primary care clinic in Seremban, Malaysia. The patients who were eligible for inclusion into the study were those aged 30-65 years and who could communicate in English, Malay or Mandarin. This study excluded patients who were pregnant, lactating, or who had severe diabetic complications that limited the testing of literacy and knowledge. Patients were approached in the clinic for participation based on convenience sampling from the diabetes registry of the clinic. They were then screened for eligibility and were asked to provide written informed consent before entering the study. The Medical Research and Ethics Committee of the Ministry of Health, Malaysia, provided ethical approval (NMRR-15-2231-27958) for the study.

\section{Demographic variables and medical history data}

A self-reported questionnaire was used to collect data on age, gender, ethnicity, level of education and the duration from the first diagnosis of diabetes. The most recent $\mathrm{HbA} 1 \mathrm{c}$ values of the participants, within the previous 6 months, were obtained from the medical records.

\section{Diabetes specific literacy}

Diabetes specific literacy was assessed using the Literacy Assessment for Diabetes (LAD), which is an instrument that is used to assess the ability to read 60 nutritional and medical terms, including terms specific to diabetes that are arranged in the order of increasing 
complexity (Nath et al., 2001). Two independent Malaysian translators backtranslated the LAD from English to both Malay and Mandarin, to complement the native language used by the patients attending the clinic. A score was given for each correct pronunciation, and the raw score was then converted into one of three reading grade levels: Fourth Grade or Malaysian Primary Standard Four and below (0-20 points); Fifth to Ninth Grade or Malaysian Primary Standard Five to Secondary Form Two (21-40 points); and Ninth Grade or Secondary Form Three and above (41-60 points).

\section{Diabetes specific knowledge}

Specific knowledge of diabetes was assessed using the Diabetes Knowledge Test 2 (DKT2), which is a 14-item test of the knowledge of diabetes for people who do not use insulin (Fitzgerald et al., 2016). This instrument assesses diabetes-related knowledge of physical activity, diabetes-related complications, nutritional management and glucose monitoring. The DKT2 was backtranslated from English to Malay and Mandarin in a similar fashion as the LAD. A score was given for each question answered correctly, and the raw score was then converted into one of three categories: low (0-7 points); acceptable (7-10 points); and good (11-14 points) (Al-Qazaz et al., 2010).

\section{Statistical analysis}

Statistical analysis was performed using the SPSS version 22 software (IBM Corp., Armonk, NY, US). Descriptive statistics (mean, standard deviation $[S D]$, median, interquartile range $[I Q R]$, frequency and percentage participants) were used to describe the characteristics of the participants, literacy scores and knowledge scores. The independent t-test was used to compare literacy and knowledge scores between genders.
The analysis of variance (ANOVA) with post-hoc Tukey's honestly significant difference (HSD) test was used to compare literacy and knowledge scores between age groups, ethnicity and educational attainment levels. A stepwise multiple regression was performed to sequentially identify the sociodemographic characteristics including gender, age, ethnicity and educational attainment levels that were most closely associated with literacy and knowledge scores, respectively. All $p$-values were two-tailed. A $p$-value of $<0.05$ was considered statistically significant.

\section{RESULTS}

A total of 723 patients were assessed for eligibility. Of these, a total of 515 were excluded as 417 were deemed ineligible and 98 declined to participate. Of the 208 patients who participated in the study, 196 participants provided complete data and were included in the analysis (Figure 1). The participants had a mean $\pm S D$ age of $55.6 \pm 7.7$ years. They were predominantly women (56.1\%), with secondary school education (61.2\%) and were of Chinese or Indian ethnicity (Malay 19.1\%; Chinese 31.1\%; Indian $49.0 \%)$. The median (IQR) duration of diagnosis with diabetes was 8.0 (9.0) years with a median $(I Q R)$ HbA1c of 8.1 (2.7) \%.

\section{Diabetes literacy and knowledge scores}

The mean diabetes literacy score of the participants as measured by the LAD was $43.8 \pm 19.6$ (mean $\pm S D$ ) points out of a possible maximum of 60 points. The majority had scores corresponding to the Ninth Grade Level (Year 9) or Malaysian secondary education of Form Three (< Fourth Grade Level or Malaysian Primary Standard Four, 16.8\%; Fifth to Ninth Grade Level or Malaysian Primary 


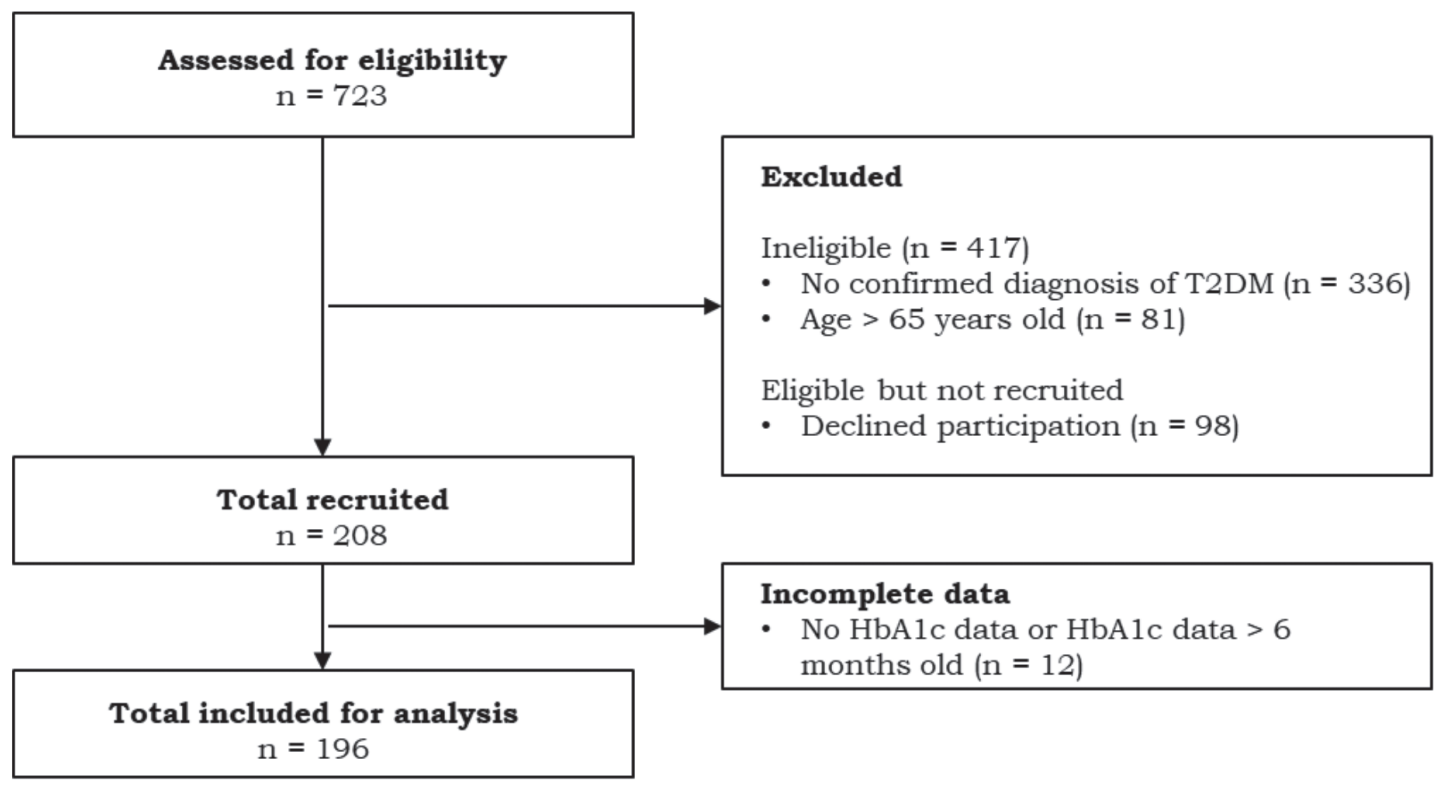

Figure 1. Flow diagram for the selection of participants of the study

Standard Five to Secondary Form Two, 8.2\%; $\geq$ Ninth Grade Level or Malaysian Secondary Form Three, 75.0\%). Knowledge of diabetes as measured by the DKT2 was $6.8 \pm 2.6($ mean $\pm S D)$ points out of a possible maximum of 14 points, and only $3.6 \%$ of participants were classified as having a good knowledge of diabetes (poor 42.9\%; average 53.6\%; good 3.6\%). LAD scores and DKT2 scores were significantly correlated, with the former explaining up to $19.8 \%$ of the variance in the latter $\left(r=0.445, r^{2}=0.198\right.$, $p<0.01$ ).

Table 1 displays the diabetes literacy and knowledge scores by participant characteristics. There was a statistically significant difference in literacy and knowledge scores between ethnicities as determined by ANOVA $(p<0.01)$. A Tukey post-hoc test revealed that Indians had significantly lower literacy and knowledge scores compared to Malays and Chinese $(p<0.05)$ and that there was no significant difference between Malays and Chinese (literacy: $p=0.630$; knowledge: $p=0.919)$. In addition, there was a statistically significant difference in literacy and knowledge scores between participants of different educational levels as determined by ANOVA $(p<0.001)$. For literacy scores, the Tukey post-hoc test showed that this difference was significant between all educational levels $(p<0.05)$ except for between no formal and primary education $(p=0.931)$, and secondary and tertiary education $(p=0.285)$. For knowledge scores, the Tukey post-hoc test showed that this difference was significant between all educational levels $(p<0.05)$ except for between no formal and primary education $(p=1.000)$, and no formal and secondary education $(p=0.471)$.

The stepwise multiple regression showed that educational level was more likely than ethnicity to predict both literacy and knowledge scores, while gender and age did not predict either literacy or knowledge scores (Table 2). There was no interaction among the characteristics of age, gender, ethnicity, 
Table 1. Diabetes literacy and knowledge scores by participant characteristics $(N=196)$

\begin{tabular}{|c|c|c|c|c|}
\hline Characteristics & $\begin{array}{c}\text { Literacy } \\
\text { scores } \\
(\text { Mean } \pm S D) \\
\end{array}$ & p-value & $\begin{array}{c}\text { Knowledge } \\
\text { scores } \\
(\text { Mean } \pm S D)\end{array}$ & p-value \\
\hline \multicolumn{5}{|l|}{ Gender } \\
\hline Women $(n=110)$ & $43.3 \pm 19.9$ & 0.713 & $6.7 \pm 2.6$ & 0.347 \\
\hline Men $(n=86)$ & $44.4 \pm 19.4$ & & $7.0 \pm 2.5$ & \\
\hline \multicolumn{5}{|l|}{ Age group } \\
\hline $30-39$ years $(n=8)$ & $42.8 \pm 19.7$ & & $6.1 \pm 2.2$ & \\
\hline $40-49$ years $(n=30)$ & $39.6 \pm 22.2$ & 0.313 & $6.8 \pm 2.4$ & 0.877 \\
\hline $50-59$ years $(n=83)$ & $42.6 \pm 20.4$ & & $6.9 \pm 2.5$ & \\
\hline $60-65$ years $(n=75)$ & $46.9 \pm 17.5$ & & $6.8 \pm 2.8$ & \\
\hline \multicolumn{5}{|l|}{ Ethnic background } \\
\hline Malay $(\mathrm{n}=39)$ & $50.7 \pm 10.4^{b}$ & & $7.5 \pm 2.4^{\mathrm{a}}$ & \\
\hline Chinese $(n=61)$ & $47.1 \pm 19.0^{\mathrm{a}}$ & 0.002 & $7.3 \pm 2.3^{\mathrm{a}}$ & 0.005 \\
\hline Indian $(n=96)$ & $38.9 \pm 21.7^{\mathrm{a}, \mathrm{b}}$ & & $6.2 \pm 2.7^{\mathrm{a}}$ & \\
\hline \multicolumn{5}{|l|}{ Level of education } \\
\hline No formal $(n=5)$ & $26.6 \pm 24.9^{a, b}$ & & $5.6 \pm 2.9^{a}$ & \\
\hline Primary $(n=57)$ & $31.6 \pm 24.0^{c}$ & $<0.001$ & $5.6 \pm 2.3^{c}$ & $<0.001$ \\
\hline Secondary $(n=120)$ & $48.7 \pm 14.4^{a, c}$ & & $7.2 \pm 2.5^{\mathrm{a}, \mathrm{c}}$ & \\
\hline Tertiary $(n=14)$ & $57.6 \pm 3.9^{\mathrm{b}, \mathrm{c}}$ & & $9.2 \pm 1.6^{\mathrm{a}, \mathrm{c}}$ & \\
\hline
\end{tabular}

The same alphabets denote significant difference: $\mathrm{a}=p<0.05 ; \mathrm{b}=p<0.01 ; \mathrm{c}=p<0.001$

and educational level. In the analysis for literacy scores, level of education and ethnicity were significantly related to literacy scores $F(2,193)=33.417$, $p<0.001$. The multiple correlation coefficient was 0.507 and $25 \%$ of the variance of literacy scores was accounted for by the level of education and ethnicity. The regression equation for predicting literacy scores was: predicted literacy scores $=8.220+0.469$ (educational level) +0.250 (ethnicity). In the analysis for knowledge scores, the level of education and ethnicity were significantly related to knowledge scores $F(2,193)=23.417$, $p<0.001$. The multiple correlation coefficient was 0.442 and $18.7 \%$ of the variance of knowledge scores was accounted for by the level of education and ethnicity. The regression equation for predicting knowledge scores was: predicted knowledge scores = $2.729+0.397$ (educational level) + 0.242 (ethnicity).

Table 2. Socio-demographic variables most closely associated with literacy and knowledge scores $(N=196)$

\begin{tabular}{|c|c|c|c|c|c|c|c|c|}
\hline \multirow{2}{*}{$\begin{array}{l}\text { Sociodemographic } \\
\text { variables }\end{array}$} & \multicolumn{4}{|c|}{ Literacy scores } & \multicolumn{4}{|c|}{ Knowledge scores } \\
\hline & b & $S E$ & $t$ & $p$-value & b & $S E$ & $t$ & p-value \\
\hline Education $^{\dagger}$ & 14.68 & 1.95 & 7.51 & $<0.001$ & 1.62 & 0.27 & 6.11 & $<0.001$ \\
\hline Ethnicity $^{\dagger}$ & 5.58 & 1.39 & 4.00 & $<0.001$ & 0.70 & 0.19 & 3.72 & $<0.001$ \\
\hline Gender & 0.11 & & 1.76 & 0.080 & -0.05 & & 0.74 & 0.460 \\
\hline Age & 0.09 & & 1.44 & 0.151 & -0.01 & & -0.20 & 0.843 \\
\hline
\end{tabular}

†Variables included in reduced models

Reduced model, literacy scores: $F(2,193)=33.417, p<0.001$ adjusted $R^{2}=0.250$

Reduced model, knowledge scores: $F(2,193)=23.417, p<0.001$ adjusted $R^{2}=0.187$ 
Table 3. Item analysis of the diabetes knowledge test of participants ( $N=196)$

\begin{tabular}{clc}
\hline Items & Diabetes knowledge tested & \% Correct \\
\hline $\begin{array}{l}\text { Physical activity } \\
9\end{array}$ & Effect of exercise on blood glucose & 62.2 \\
Diabetes-related complications & \\
14 & Identification of complications - eye, kidney, nerve & 66.8 \\
11 & Diabetes self-care practice - foot care \\
12 & Prevention of macrovascular complications - heart & 65.3 \\
& disease & 63.3 \\
13 & Detection of microvascular complications - nerve disease & 56.6 \\
10 & Effect of infection on blood glucose levels & 10.7 \\
Nutritional management & \\
1 & Description of diabetes diet and healthy eating \\
2 & Identification of carbohydrate-rich foods & 61.7 \\
3 & Identification of high-fat foods & 49.0 \\
8 & Dietary management of hypoglycaemia & 33.7 \\
7 & Effect of unsweetened fruit juice on blood glucose & 28.1 \\
4 & Identification of "free food" & 24.5 \\
& & 23.0 \\
Glucose monitoring & \\
6 & Self-monitoring of blood glucose & \\
5 & Glucose testing - HbAlc & 36.2 \\
\hline
\end{tabular}

Diabetes knowledge - item analysis Table 3 shows the number of correct responses to each question of the DKT2. More than $60 \%$ of the participants were able to correctly answer the question regarding physical activity (Item 9). On the subject of diabetes-related complications, $>60 \%$ of the participants correctly answered questions regarding identification of complications (Item 14), diabetes self-care practice (Item 11), prevention of macrovascular complications (Item 12), and detection of microvascular complications (Item 13). However, only $10.7 \%$ of the participants correctly identified that an infection will most likely raise blood glucose (Item 10).

Responses to questions on the nutritional management of diabetes indicated that the majority of participants $(61.7 \%)$ correctly answered the question on diabetes diet and healthy eating (Item 1). However, they had limited knowledge about food groups and the effect of food on blood glucose. While $49.0 \%$ of the participants could correctly identify carbohydrate-rich foods (Item 2), only $33.7 \%$ of the participants could correctly identify low-fat milk as being highest in fat among carbohydrate-rich food such as orange juice, corn, and honey (Item 3). The participants also had poor knowledge of hypoglycaemia management as only $28.1 \%$ correctly identified food or beverage portions containing 15 grams of simple carbohydrates (Item 8). About a quarter of participants $(24.5 \%)$ correctly indicated that unsweetened fruit juices increase blood glucose (Item 7) and only $23.0 \%$ of the participants correctly identified that 'free food' (food items on the diabetes exchange list that are very low in calories and contain a very small amount of carbohydrates) contains $<20$ calories per serving (Item 4). 
On the subject of diabetes monitoring, $54.6 \%$ of the participants correctly indicated that blood glucose as opposed to urine checking was the better method for checking glucose at home (Item 6). However, only $36.2 \%$ of the participants correctly knew that $\mathrm{HbA} 1 \mathrm{C}$ was a measure of average blood glucose levels for the past 6-12 weeks (Item 5).

\section{DISCUSSION}

The socio-demographic characteristics of the participants from this study mirrored that which was seen in the registry data of the study site. However, the ethnic composition of participants in this study differed from the patient demographics in hospital-based outpatient centres across Malaysia. The participants in this study were predominantly of Indian or Chinese ethnicity. In contrast, the DiabCare 2013 study showed that patients with diabetes in Malaysia were mainly from the Malay ethnic group, followed by Chinese and Indian in similar proportions (Mafauzy et al., 2016). Ethnicity can influence health literacy and knowledge outcomes when language and cultural differences exist between the patient and healthcare system (Nelson, Stith \& Smedley, 2002). Thus care should be taken when generalising the results of this study to the Malaysian populace.

Consistent with other findings, $>2 / 3$ of the participants from this study presented with health literacy equivalent to secondary school education (Osborn, Bains \& Egede, 2010; Bohanny et al., 2013). This study also found that health literacy was positively associated with diabetes knowledge, echoing results from a meta-analysis on these variables (Marciano, Camerini \& Schulz, 2019). This finding indicates the need to tailor diabetes education to the level of health literacy of the patient, as knowledge is associated with appropriate self-care and health outcomes (Kueh, Morris \& Ismail,
2016). In this study, participants who had a lower level of education and those of Indian ethnicity had lower literacy and poorer knowledge scores when compared to patients of other ethnic groups. In Malaysia, the prevalence of diabetes is highest among Indians when compared to other ethnic groups (Rampal et al., 2010). The low levels of literacy and knowledge among Indians shown in this study are of concern, as this may be a hindrance to the better management of diabetes among these patients.

Despite having adequate literacy to acquire and use health information, the participants from this study had lower diabetes knowledge scores when compared to those of other studies (A1Qazaz et al., 2010; Fitzgerald et al., 2016). The participants from this study could answer general questions about physical activity, diabetes-related complications and healthy eating. However, diabetesrelated knowledge of specific food groups and the effect of diet on glucose control was limited among participants of this study. These findings reflect the current diabetes education situation in Malaysia. In most hospitals, diabetes nurse-educators deliver information on the general management of diabetes and self-care practices via established Diabetes Resource Centers (Zanariah et al., 2015). The provision of education on nutrition is nonetheless limited to general nutrition and healthy eating. In this study, majority of the participants could not identify food sources of carbohydrate and fat. Instead, they had misconceptions about food that could be incorporated ad-libitum into their diet.

Local studies on the knowledge of diabetes-related nutrition among Malaysian diabetics are scarce. However, the findings of local studies suggest that Malaysians with diabetes tend to consume a diet that is high in carbohydrate and fat (Norimah \& Abu Bakar, 1993; Moy \& Rahman, 2002; Chin 
et al., 2013), hinting at a poor knowledge of diabetes-related nutrition. The lack of diabetes-related nutrition knowledge among patients is not isolated and has also been shown in other patients, for example, those from China. The study by Zijian et al. (2017) showed that Chinese patients with diabetes generally had a poor understanding of practices related to medical nutrition therapy. The Chinese patients who had better knowledge, attitude, and practice scores, exhibited better control of blood glucose (Zijian et al., 2017). Nutrition education strategies that provide instructions beyond general healthy eating, such as carbohydrate calorie counting, have been shown to improve glycaemic control in both patients with type $1 \mathrm{DM}$ and T2DM (Kitajima et al., 2016; Brake, 2017). Among Malaysian adult patients with T2DM, specific nutritional education led to significant weight loss and improved HbA1C (Arasu et al., 2016).

This study had several limitations. While the instruments that were used to assess literacy and knowledge levels had been validated in Englishspeaking populations (Nath et al., 2001; Fitzgerald et al., 2016), the translated Malay and Mandarin versions were not validated for use among Malaysians. As such, the results of this study may be subject to errors of measurement. Secondly, this study did not look at the access to healthcare provision, the attendance at educational classes on diabetes or consultations with diabetes nurse-educators or dietitians. Access to healthcare amenities and contact with a healthcare provider are associated with literacy and knowledge status of patients with diabetes (Fenwick et al., 2013; Bailey et al., 2014).

Trained interviewers administered the LAD and DKT2 tools by using face-to-face interviews in order to reduce the cognitive demand on the participants. The development of self- administered electronic tools that take into consideration literacy requirements can help reduce the resource burden of future studies in this area. Knowledge may not directly predict patient behavior but it is a prerequisite for appropriate self-care. This study, however, did not look at the association between diabetes-related literacy and knowledge, and actual self-care behaviour. Further research is needed to identify gaps between knowledge and practice that may exist among Malaysian patients with diabetes. The current burden of diabetes and its future implications warrant the need for educational programmes in diabetes that are tailored to the literacy and cultural environment of high-risk subjects as main target groups (Rampal et al., 2010). In addition, the gaps in the knowledge of diabetes-related nutrition that exists among the participants of this study present an opportunity for appropriate interventions.

\section{CONCLUSION}

The participants of this study had fairly good diabetes-specific literacy to process health information. The study results also indicated that educational level and ethnicity were key factors for poor diabetes literacy and knowledge. There also existed nutrition-related knowledge deficits among the study participants. These findings should help healthcare providers tailor individualised patient education interventions.

\section{Acknowledgement}

This study was supported by a research grant from the International Medical University (IMU), Kuala Lumpur, Malaysia. Five student dietitians from IMU - Hoo Pui Wen, Wong Lai Mun, Clara Law Wan Yin, Amanda Chew Yan, and Chin Lock See, assisted in the collection of the data that was used in this study.

\section{Authors' contributions}

LCL, the principal investigator, conceptualised and designed the study, led the data collection, data 
analysis and interpretation, prepared the draft of the manuscript and reviewed the manuscript; WCSS, designed the study, supervised the data collection, advised on the data analysis and interpretation and reviewed the manuscript; KA, designed the study, supervised the data collection, conducted data analysis and interpretation and reviewed the manuscript; KSK, designed the study, supervised the data collection, advised on the data analysis and interpretation and reviewed the manuscript; SZA, designed the study, supervised the data collection and reviewed the manuscript.

\section{Conflict of interest}

The authors have no conflict of interest to declare.

\section{References}

Al-Qazaz HK, Hassali MA, Shafie AA, Sulaiman SAS \& Sundram S (2010). The 14-item Michigan Diabetes Knowledge Test: translation and validation study of the Malaysian version. Pract Diabetes Int 27(6):238-242.

Arasu K, Karupaiah T, Chee WSS, Chinna K, \& Wong K (2016). Effect of dietary intervention on anthropometric measurements and glycemic control of individuals with type 2 diabetes mellitus in primary healthcare. In Malaysian Dietitians Association-Asian Overseas Dietitians Association Conference. Kuala Lumpur, Malaysia.

Bailey SC, Brega AG, Crutchfield TM, Elasy T, Herr $\mathrm{H}$, Kaphingst K, Karter A, Moreland-Russell S, Osborn CY, Pignone M, Rothman R \& Schillinger D (2014). Update on health literacy and diabetes. Diabetes Educ 40(5):581-604.

Bains SS \& Egede LE (2011). Associations between health literacy, diabetes knowledge, self-care behaviors, and glycemic control in a low income population with type 2 diabetes. Diabetes Technol Ther 13(3):335-341.

Bohanny W, Wu SFV, Liu CY, Yeh SH, Tsay SL \& Wang TJ (2013). Health literacy, self-efficacy, and self-care behaviors in patients with type 2 diabetes mellitus. J Am Assoc Nurse Pract 25(9):495-502.

Brake J (2017). Carbohydrate counting: a locally developed structured education course in Liverpool. J Diabetes Nurs 21(7):250-254.

Chin KH, Sathyasurya DR, Hazizi Abu S \& Hamid Jan BJB (2013). Effect of ethnicity, dietary intake and physical activity on plasma adiponectin concentrations among Malaysian patients with type 2 diabetes mellitus. Int $J$ Endocrin Metab 11(3):167-174.
Fenwick EK, Xie J, Rees G, Finger RP \& Lamoureux EL (2013). Factors associated with knowledge of diabetes in patients with type 2 diabetes using the diabetes knowledge test validated with Rasch analysis. PLOS ONE 8(12):8-14.

Fitzgerald JT, Funnell MM, Anderson RM, Nwankwo R, Stansfield RB \& Piatt GA (2016). Validation of the revised brief Diabetes Knowledge Test (DKT2). Diabetes Educator 42(2):178-187.

IPH (2015). National Health and Morbidity Survey 2015 Non-communicable diseases, risk factors and other health problems (Vol. 2). Institute for Public Health, Ministry of Health Malaysia, Kuala Lumpur; 2019. From http://www.moh. gov.my/moh/resources/nhmsreport2015vol2. pdf. [Retrieved December 30 2019].

Kitajima Y, Mikami N, Hyodo T, Hida M \& Kawakami J (2016). Carbohydrate counting: a simple method of dietary management for glycemic control in japanese diabetic hemodialysis patients. Contrib Nephrol 189:262-269.

Kueh YC, Morris T \& Ismail AAS (2016). The effect of diabetes knowledge and attitudes on self-management and quality fo life among people with type 2 diabetes. Psychol Hlth Med 22(2):138-144.

Letchuman GR, Wan Nazaimoon WM, Wan Mohamad WB, Chandran LR, Tee GH, Jamaiyah H, Isa MR, Zanariah H, Fatanah I \& Ahmad Faudzi Y (2010). Prevalence of diabetes in the Malaysian National Health Morbidity Survey III 2006. Med J Malaysia 65(3):173179.

Mafauzy M, Zanariah H, Nazeri A \& Chan SP (2016). DiabCare 2013: A cross-sectional study of hospital based diabetes care delivery and prevention of diabetes related complications in Malaysia. Med J Malaysia 71(4):77-185.

Marciano L, Camerini AL \& Schulz PJ (2019). The role of health literacy in diabetes knowledge, self-care, and glycemic control: a metaanalysis. J Gen Intern Med. DOI:10.1007/ s11606-019-04832-y

Moy FM \& Rahman SA (2002). Anthropometry and dietary intake of type 2 diabetes patients attending an outpatient clinic. Mal $J$ Nutr 8(1):63-73.

Nath CR, Sylvester ST, Yasek V \& Gunei E (2001). Development and validation of a literacy assessment tool for persons with diabetes. Diabetes Educ 27(6):857-864. 
Nelson AR, Stith AY \& Smedley BD (2002). Unequal treatment: confronting racial and ethnic disparities in health care. National Academies Press, Washington DC.

Nielsen-Bohlman L, Panzer AM \& Kindig KA (2004). Health Literacy. National Academies Press, Washington DC. From https://doi. org/10.17226/10883. [Retrieved March 30 2019].

Norimah AK \& Abu Bakar AAH (1993). Food intake and anthropometric status of diabetics attending Universiti Kebangsaan Malaysia (UKM) outpatient clinic. Proc Nutr Soc Mat $8: 16 \mathrm{e} 22$.

Osborn CY, Bains SS \& Egede LE (2010). Health literacy, diabetes self-care, and glycemic control in adults with type 2 diabetes. Diabetes Technol Ther 12(11):913-919.

Phillips E, Rahman R \& Mattfeldt-Beman M (2018). Relationship between diabetes knowledge, glycemic control, and associated health conditions. Diabetes Spectr 31(2):196-199.

Powell CK, Hill EG \& Clancy DE (2007). The relationship between health literacy and diabetes knowledge and readiness to take health actions. Diabetes Educator 33(1):144151.

Rajah R, Hassali MAA \& Murugiah MK (2019). A systematic review of the prevalence of limited health literacy in Southeast Asian countries. Publ Hlth 167:8-15.
Rampal S, Rampal L, Rahmat R, Azhar MZ, Yap YG, Mafauzy M \& Mohamad T (2010). Variation in the prevalence, awareness, and control of diabetes in a multiethnic population: a nationwide population study in Malaysia. Asia Pac J Publ Hlth 22(2):194-202.

Saeed H, Saleem Z, Naeem R, Shahzadi I \& Islam M (2018). Impact of health literacy on diabetes outcomes: a cross-sectional study from Lahore, Pakistan. Publ Hlth 156:8-14.

Whiting DR, Guariguata L, Weil C \& Shaw J (2011). IDF diabetes atlas: global estimates of the prevalence of diabetes for 2011 and 2030. Diabetes Res Clin Pract 94(3):311-321.

Zanariah H, Sri Wahyu T, Gilcharan Singh HK \& Chee WSS (2015). Diabetes care in Malaysia: problems, new models, and solutions. Ann Glob Health 81(6):851-862.

Zijian L, Haimin J, Chen W, Zilin S, Jing L, Zhao X, Zhu S, Guo X \& China NEEDs Study Group (2017). Influencing factors of knowledge, attitude, and practice regarding medical nutrition therapy in patients with diabetes: A national cross-sectional study in urban China. $J$ Diabetes Res 9(9):865-873. 